\title{
The Many Faces of a Monogenic Autoinflammatory Disease: Adenosine Deaminase 2 Deficiency
}

\author{
Jennifer Lee Kendall $^{1} \cdot$ Jason Michael Springer ${ }^{1}$ \\ Published online: 26 August 2020 \\ (C) Springer Science+Business Media, LLC, part of Springer Nature 2020
}

\begin{abstract}
Purpose of Review We aim to describe the pathophysiology, clinical findings, diagnosis, and treatment of deficiency of adenosine deaminase 2 (DADA2).

Recent Findings DADA2 is a multi-organ disease of children and less often adults, which can present with wide-ranging manifestations including strokes, medium vessel vasculitis, hematologic disease, and immunodeficiency. Diagnosis is through detection of reduced activity level of the adenosine deaminase 2 (ADA2) enzyme and/or identification of bi-allelic mutations in the ADA2 gene. Outside of high-dose glucocorticoids, conventional immunosuppression has been largely ineffective in treating this relapsing and remitting disease. Vasculitic-predominant manifestations respond extremely well to tumor necrosis factor- $\alpha$ inhibition. Hematopoietic stem cell transplantation can lead to normalization of enzyme activity, as well as resolution of vasculitic, hematologic, and immunologic manifestations, although treatment-related adverse effects are not uncommon.

Summary Early detection of this disease across multiple disciplines could prevent devastating clinical outcomes, especially in genetically pre-disposed populations.
\end{abstract}

Keywords Adenosine $\cdot$ Adenosine deaminase 2 deficiency $\cdot$ Vasculitis $\cdot$ Polyarteritis nodosa $\cdot$ Monogenic disease

\section{Introduction}

Deficiency of adenosine deaminase 2 (DADA2) is a monogenic autoinflammatory disorder that affects multiple organ systems with highly variable clinical presentations. First described in 2014 by two separate groups as a mimic of polyarteritis nodosa (PAN), there have been over 260 cases of DADA2 identified to date $[1 \bullet \bullet, 2 \bullet \bullet]$. Abnormalities in adenosine breakdown play a key role in the pathogenesis.

This article is part of the Topical Collection on Vasculitis

Jason Michael Springer

jasonspringer79@hotmail.com

Jennifer Lee Kendall

jlkend@gmail.com

1 Division of Allergy, Clinical Immunology and Rheumatology, Department of Medicine University of Kansas Medical Center, 3901 Rainbow Blvd MS 2026, Kansas City, KS 66160, USA

\section{Pathophysiology of DADA2}

Adenosine is formed by the breakdown of adenine nucleotides, with increased concentrations seen in the setting of cellular damage [3, 4]. The effect of adenosine is mediated by four $G$ protein-coupled cell surface receptors $\left(A_{1}, A_{2 A}, A_{2 B}\right.$, and $\left.A_{3}\right)$, present on many different cell types [5••]. Receptor activation triggers either a decrease $\left(A_{1}\right.$ and $\left.A_{3}\right)$ or increase $\left(\mathrm{A}_{2 \mathrm{~A}}\right.$ and $\left.\mathrm{A}_{2 \mathrm{~B}}\right)$ in intracellular cyclic AMP, which then mediates a change in cellular activation [3]. The varying effect of adenosine on cellular activity and local inflammation seems to be determined by the interplay between the local adenosine concentration, degree of cellular receptor expression, receptor type, and the receptor affinity; most of which can be affected by environmental factors [5••]. Drugs that manipulate the adenosine pathway can be effective in inflammatory diseases [4].

The adenosine deaminases catalyze the deamination of adenosine to inosine, and deoxyadenosine to deoxyinosine, a key part of the purinergic pathway [6••] (Fig. 1). There are two primary isoforms of adenosine deaminase in humans, adenosine deaminase (ADA) 1 and 2. The major adenosine deaminase in humans is ADA1, a $40-\mathrm{kDa}$ monomer present in 


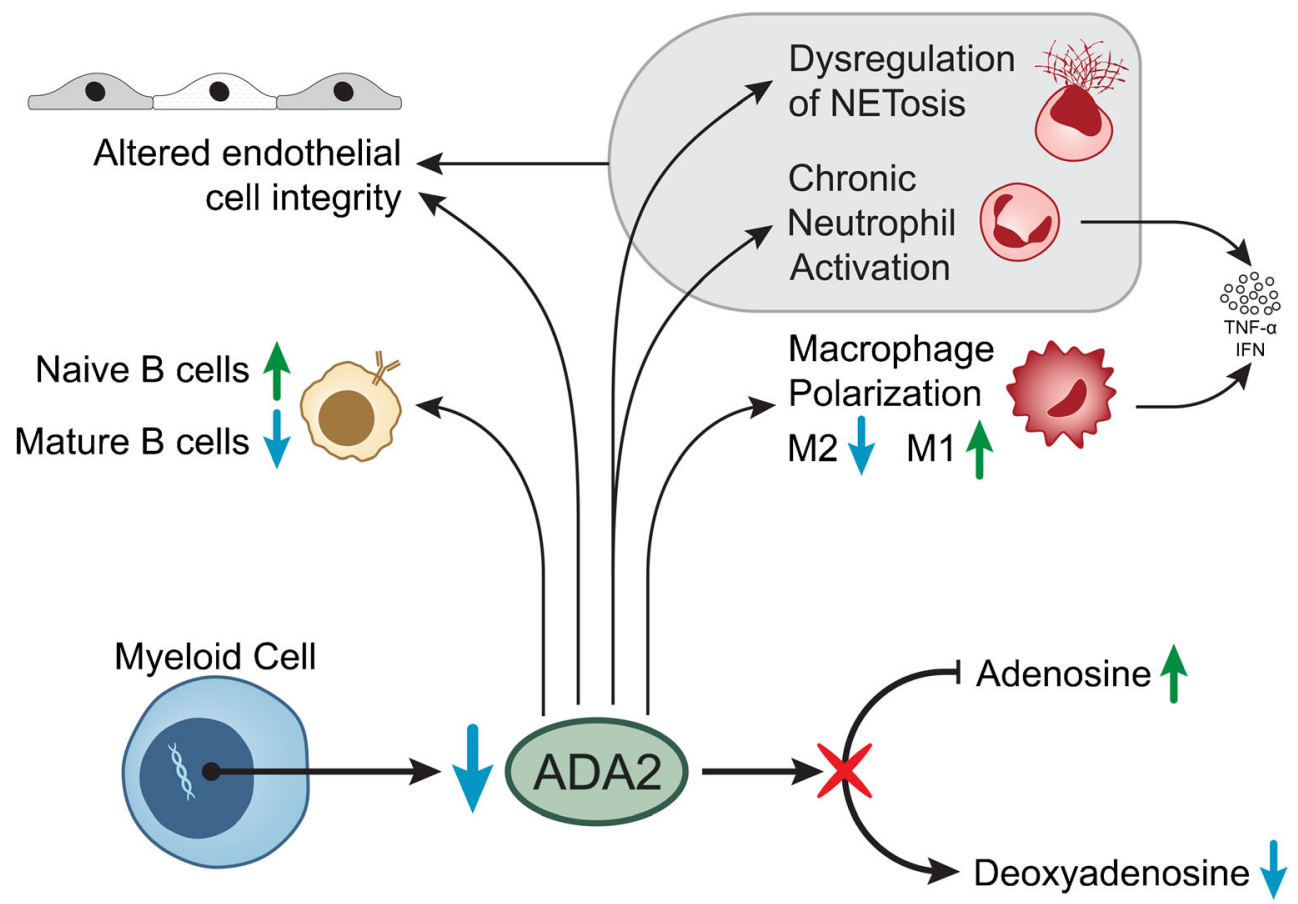

Fig. 1 Proposed pathophysiology of deficiency of adenosine deaminase 2 (DADA2). Adenosine deaminase 2 (ADA2) is produced by myeloid cells with a reduction in enzyme level and/or enzyme activity level. Insufficient ADA2 activity leads to reduction in deamination of adenosine to deoxyadenosine, and an accumulation of extracellular adenosine. Dysregulation of NETosis, chronic neutrophil activation, and polarization from the M2 macrophage subtype to the pro-

almost all cells, functioning to reduce levels of adenosine in the intracellular space, as high levels are cytotoxic [6••]. Known as severe combined immunodeficiency (SCID), lossof-function mutations in the ADA1 gene lead to increased apoptosis of $\mathrm{T}$ and $\mathrm{B}$ cells, resulting in recurrent infections [7]. ADA2 is present only at low levels in the physiologic state, increasing during periods of stress [6••]. Unlike ADA1, ADA2 is a $57-\mathrm{kDa}$ homodimer, secreted into the extracellular space, with low affinity for adenosine in physiologic conditions, although this can change based on temperature and $\mathrm{pH}[6 \cdot \bullet]$. Structurally, while ADA1 and ADA2 have somewhat similar catalytic domains, ADA2 has additional domains allowing it to mediate protein dimerization and cell surface binding in the extracellular space [8••]. The protein dimerization domain is structurally homologous with a family of adenosine deaminase growth factors [6••], which have been shown to be critical in the development of frog [9] and fly [10] embryos. ADA2 has been proposed to have a role in endothelial cell and hematopoietic cell development, although this enzyme is not present within human endothelial cells [2••, $6 \bullet \bullet, 8 \bullet \bullet$. Endothelial cell instability in patients with DADA2 is felt to predispose to an underlying vasculitic phenotype $[1 \bullet \bullet$, $2 \bullet \bullet$. ADA2 is predominantly expressed by monocytes undergoing $\mathrm{T}$ cell-dependent differentiation into macrophages and dendritic cells $[11 \bullet \bullet]$. ADA2 seems to also have cytokine-like inflammatory M1 subtype leads to increased inflammatory cytokine production including Tumor Necrosis Factor- $\alpha$ (TNF- $\alpha)$, Interferon (IFN), and (in smaller cohorts) interleukin (IL)-6, IL-8, and IL-10. Dysregulation of NETosis and chronic neutrophil activation may also contribute toward decreased endothelial cell integrity. Increased numbers of naïve $\mathrm{B}$ cells with decreased mature $\mathrm{B}$ cells have been noted in DADA2

growth factor properties, namely by activating CD4+ T cells and monocytes via cell surface binding and formation of the immunological synapse [11••]. ADA2 is also felt to have autocrine-type growth factor properties by stimulating macrophage proliferation and inducing $\mathrm{T}$ cell-dependent differentiation of monocytes to macrophages [11••]. ADA2 binds to different cell types via cell surface proteoglycans, but can bind specifically to $\mathrm{T}$ cells via the adenosine receptors $[11 \bullet \bullet]$. ADA2 binds preferentially to specific lymphocyte subsets without receptors more specific to ADA1 [5••].

Neutrophils have adenosine receptors. A chronic upregulation of neutrophil activity has been proposed to also be behind the vasculopathy component of DADA2 based on findings of upregulated interferon-stimulated gene transcripts in peripheral blood and overexpression of neutrophil-derived genes in two DADA2 patients. Neutrophil activation could contribute to reduced endothelial cell integrity [12]. Changes in the adenosine metabolism pathways cause dysregulation of neutrophil extracellular trap formation (i.e., NETosis) in patients with DADA2 [13••]. Increased NETosis has been identified in mesenteric artery tissue with myeloid-cell predominant inflammation $[13 \bullet \cdot]$. Increased circulation of low-density granulocytes, a subset of neutrophils with propensity for NETosis, was also increased in patients with DADA2 [13••]. NETosis also increases macrophage release of TNF- $\alpha[13 \cdot 0]$. 
Dysregulation of the NETosis can also be seen in other autoimmune diseases, specifically systemic lupus erythematosus and ANCA-associated vasculitis [14, 15] (Fig. 1).

DADA2 patients have demonstrated a shift in differentiated myeloid cells toward a prominence of pro-inflammatory M1 macrophages, likely tied to ADA2's physiologic role in maintaining the balance of myeloid lineage cells and their differentiation $[2 \bullet \bullet]$. This polarization of the monocytemacrophage population is felt to cause a release of proinflammatory cytokines and lead to downstream tissue damage $[2 \bullet \bullet, 16]$.

Upregulation of several key pro-inflammatory cytokines has been identified in patients with DADA2. Increased TNF- $\alpha$ has been seen both peripherally and in affected tissues $[1 \bullet \bullet, 17 \bullet]$. TNF- $\alpha$ secretion is thought to come predominantly from pro-inflammatory macrophages and chronically activated neutrophils $[2 \bullet \bullet, 12]$. The increased TNF- $\alpha$ production in these patients is felt to be a large part of the reason for the efficacy of TNF- $\alpha$ inhibition in DADA2 patients, especially those with vasculitic phenotypes. Increased TNF- $\alpha$ levels has also been proposed as a mechanism behind hematologic manifestations of the disease, as TNF- $\alpha$ may have a role in bone marrow failure in patients with aplastic anemia [18]. Patients with DADA2 also have upregulation of type 1 interferonstimulated genes $[12,19,20 \bullet, 21,22]$. Type 1 interferons decreases after treatment [19] and may be useful as a biomarker for DADA2 activity. Additional elevated peripheral cytokines have included IL-6 [23-25, 26•], IL-8 [25], and IL-10 [27, 28] (Fig. 1).

In the physiologic state, ADA2 binds to neutrophils, monocytes, NK cells, and the CD16 subset of macrophages. A decrease in NK, NKT, and CD16-positive monocytes was found to be common in many DADA2 patients [5••]. Several studies have found depletion of memory B cells, while naïve B cell subsets are present in increased or normal levels

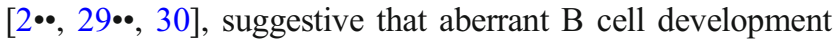
and differentiation is also part of the pathogenesis of DADA2 (Fig. 1).

\section{Clinical Manifestations of DADA2}

Since its discovery, the phenotype of DADA2 has significantly broadened to include not only vasculitis but also immunodeficiency and hematologic manifestations. Ocular involvement is highly variable, with many symptoms likely secondary to underlying cerebrovascular disease, such as vision loss and oculomotor palsies [20• $31 \bullet]$, including internuclear ophthalmoplegia. Additional ocular involvement has included strabismus [27, 32•], conjunctivitis [33], uveitis, papillitis $[20 \bullet]$, and optic neuritis $[17 \bullet, 32 \bullet, 34]$. Vasculitis of the temporal artery has been described in a 6 -year-old girl with histologic changes mimicking giant cell arteritis [35]. Hearing loss, including neurosensory hearing loss $[17 \bullet, 36]$, has been described as well.

Neurologic involvement is estimated to occur in 50-77\% of patients [32•, 37•, 38, 39•, 40•]. A key characteristic neurologic manifestation has been central nervous system (CNS) arterial infarctions in pediatric patients with PAN-like manifestations, in contrast with classic childhood PAN, in which CNS disease is less common [41•]. Both ischemic and hemorrhagic CNS infarctions have been described. In a cohort of 12 Turkish patients with DADA2 with neuroimaging, the most common lesions were acute and/or chronic lacunar infarcts in the brainstem and/or deep gray matter (75\%), with up to $50 \%$ revealing findings compatible with recurrent ischemic infarcts [34]. Several cases have suggested that cerebral MRI may be normal early on or under-report the true burden of disease [22, 42]. Additionally, conventional cerebral angiography of the CNS has been found normal in patients with ischemic lesions on MRI, again suggestive that there may be a predominance of CNS small vessel vasculitis in this subset of patients [43-45]. Alternatively, vasospasm may cause ischemia and/or reduced vascular integrity in the absence of inflammation, contributing to strokes with a paucity of findings on conventional angiogram, but consistent clinical and MRI findings [45]. DADA2 can also mimic Sneddon syndrome when presenting with livedo reticularis and neurologic manifestations [30]. Meningitis and encephalitis have been reported [31•]. Up to $53 \%$ of patients with DADA2 may have peripheral nervous system (PNS) involvement which can include mononeuritis multiplex, cranial neuropathies, and polyneuropathy (sensory or motor) $[17 \bullet, 31 \bullet, 38,39 \bullet, 46]$.

Direct cardiopulmonary involvement is less common. Cardiac involvement specifically has included pericarditis, myocarditis, cardiomyopathy, long QT syndrome, and aortic root enlargement $[17 \bullet, 40 \bullet, 47,48]$. Cavitary lung lesions, ARDS, and pleuritis have been described, in addition to recurrent pneumonias in the setting of immunodeficiency and cytopenias [20•, 32•, 37•, 49].

Visceral organ and gastrointestinal manifestations can include colicky abdominal pain, mesenteric ischemia, mesenteric artery aneurysms, hepatic artery aneurysms, gastrointestinal perforation, pancreatitis, portal hypertension, hepatoportal sclerosis, hepatosplenomegaly, and intestinal amyloidosis $[31 \bullet, 32 \bullet, 40 \bullet, 42,50]$. By both imaging and histology, mesenteric, and renal aneurysms are largely indistinguishable from PAN. A 17-year-old male with a homozygous ADA2 mutation (G47A) and heterozygous for a Familial Mediterranean Fever (FMF) genetic mutation (V276A) was found to have aneurysmal changes of the abdominal veins [51]. Isolated hepatic involvement in the form of hepatomegaly ranges from 19 to $27 \%$ [17•, 29••, 52], and hepatitis was found to be present in $36 \%$ of patients [29••]. Nodular regenerative hyperplasia has been seen most frequently on liver biopsy [42]. Notably, CVID patients have also been shown 
to have nodular regenerative hyperplasia and autoimmune hepatitis, suggesting a potential similar mechanism in these cohorts [42]. Splenic artery irregularities have also been demonstrated [50]. Hypertension has been well described in DADA2 patients, even in those with hematologic phenotypes [27, 40 $]$. Reports of renal involvement have included renal artery aneurysms, segmental glomerulosclerosis (collapsing variant), and renal amyloidosis [32•, 50, 53]. One Turkish pediatric patient with renal amyloidosis was concurrently found to be heterozygous for the FMF gene (Met694Val mutation) and responsive to canakinumab [53].

Cutaneous manifestations are common, ranging from livedo reticularis/racemosa, nodular lesions, soft tissue/ subcutaneous edema, ulcers, and erythema-multiforme-like lesions $[31 \cdot 54,55]$. The prevalence of livedo racemosa has been reported to be as high as $73 \%$ of patients [39॰]. Skin biopsies can show medium vessel vasculitis, as seen in PAN, or leukocytoclastic vasculitis [17•].

Less specific symptoms, including recurrent fevers, myalgias, arthralgias, arthritis, and oral aphthosis, are well described. There have been isolated cases of myositis [17•, $20 \bullet, 29 \bullet \bullet, 31 \bullet, 56 \bullet, 57,58]$.

Hematologic and immunodeficiency phenotypes were recognized later, with manifestations appearing to be closely linked. Pure red cell aplasia (PRCA), hemolytic anemia, autoimmune neutropenia, isolated refractory thrombocytopenia, and pancytopenia have all been reported $[26 \bullet, 27,28,31 \bullet, 37 \bullet$, $49,57,59,60]$. Bone marrow biopsy in one DADA2 patient with bicytopenia revealed myelofibrosis [32•]. In a separate cohort of five patients, two with PRCA had bone marrow studies consistent with PRCA, while one with hemolytic anemia had a hypercellular marrow, and the fourth who presented with recurrent fevers and pancytopenia had a normocellular marrow [37•]. Cytopenia-predominant disease has been closely linked to immune deficiency, with findings of memory B cell deficiency and decreased B cell differentiation in these patients $[2 \bullet \bullet, 29 \bullet \bullet, 30,61]$. The concurrence of DADA2 and lymphoproliferative diseases has been reported in several cases. Childhood onset Hodgkin's lymphoma has been described in three patients, two of which were siblings [42, 62]. Two patients have been described with $T$ cell large granular lymphocytic lymphoproliferation [49]. One patient presented with a syndrome resembling multicentric Castleman disease, responding well to anti-IL6 therapy [24].

Immunodeficiency can be mild (more commonly seen in vasculitis-predominant disease), or more severe (more commonly seen in hematologic-predominant disease). Varying degrees of antibody deficiencies can be seen including pure antibody deficiency or pan-hypogammaglobulinemia as in CVID $[17 \bullet, 29 \bullet \bullet, 32 \bullet, 49,63,64 \bullet \bullet, 65,66]$. Verrucosis, herpes virus infections, and an increased susceptibility to infection with dsDNA viruses have been reported $[26 \bullet, 49,61,67,68]$. In a study screening 181 adolescent and adult patients with antibody deficiency or CVID, 11 patients were identified with mutations in the ADA2 gene. Within this cohort, upper and lower respiratory infections were slightly more common than herpes, intestinal, or urinary tract infections [29・•]. Hypergammaglobulinemia has been reported in four patients, two of which a had strongly elevated ANA as well as lupus-like features including discoid skin lesions, oral ulcerations, photosensitivity, non-erosive arthritis, and cerebrovascular disease with elevated interferon signature [21]. The other two siblings with hypergammaglobulinemia had IL-17RA deficiency [33].

Overlap with other inherited disorders has been noted, often incidentally. A Turkish cohort of 196 patients with systemic autoinflammatory diseases screened for ADA2 mutations found two patients with pathogenic mutations and four with mutations of undetermined significance, three of which also had mutations in the FMF gene as well [69]. FMF gene mutations in patients with DADA2 have been seen by other groups as well [53]. Both FMF and DADA2 are known to have increased allele frequency in the Turkish population, possibly explaining their co-occurrence in this population. Noonan Syndrome-like disorder with loose anagen hair [70] and X-linked recessive nephrolithiasis (i.e., Dent's disease) [71] have been described. Two siblings with chronic mucocutaneous candidiasis, retinal vasculitis, elevated IgG, and neutropenia were found to have a $770-\mathrm{kb}$ deletion on chromosome 22q11.1 encompassing both the IL17 receptor gene and ADA2 [33] (Table 1).

\section{Genetic Mutations within the ADA2 Gene}

ADA2 was purified in 2005 and determined to be encoded by the ADA2 gene (formally CECR1), located on chromosome $22 q 11.1[6 \bullet \bullet, 23]$. A variety of types of mutations have since been reported including missense, nonsense, splice site mutations, frameshift mutations, deletions, and copy number variations [16, 61, 70]. Between 2014 and 2020, at least an additional 67 known pathogenic mutations were documented, with a total of 98 known variants, many not classified, of uncertain significance, or potentially benign [72••].

Several genotype-phenotype correlations have been proposed, however, such correlations are complicated by newly discovered phenotypic manifestations, epigenetics, incomplete penetrance, environmental factors affecting gene expression, and compound heterozygosity for two different mutations. Vasculitis-predominant phenotypes more commonly had missense mutations and at least some residual enzymatic activity of ADA2 (around 3\%), while those with pure red cell aplasia and bone marrow failure were more likely to have mutations leading to complete loss of function of the enzyme and/or minimal residual enzyme activity, including insertions/deletions, nonsense, or missense mutations $[73 \bullet \bullet]$. While there are some genotypes that 
Table 1 Clinical manifestations reported to date in DADA2

\begin{tabular}{|c|c|c|c|}
\hline \multicolumn{2}{|l|}{ Vasculitis } & \multirow{2}{*}{$\begin{array}{l}\text { Hematologic } \\
\text { Splenomegaly }\end{array}$} & \multirow{2}{*}{$\begin{array}{l}\text { Immunodeficiency } \\
\text { Pure antibody deficiency }\end{array}$} \\
\hline Fever & HEENT & & \\
\hline Arthralgia/arthritis & Oral aphthosis & Lymphadenopathy & $\begin{array}{l}\text { Pan-hypogammaglobulinemia } \\
\text { (including CVID) }\end{array}$ \\
\hline Myalgia/myositis & Sensorineural hearing loss & Hepatomegaly & Hypergammaglobulinemia \\
\hline Genitourinary & Temporal artery vasculitis & Pure red cell aplasia & Meningitis \\
\hline Testicular infarction & Vision loss & Hepatoportal sclerosis & Eczema \\
\hline Hypertension & Oculomotor palsies & Hemolytic anemia & Encephalitis \\
\hline Renal artery aneurysms & Strabismus & Portal hypertension & Verrucosis \\
\hline Segmental glomerulosclerosis & Conjunctivitis & Autoimmune neutropenia & $\begin{array}{l}\text { Upper and lower respiratory } \\
\text { infections }\end{array}$ \\
\hline Renal amyloidosis & Optic neuritis & Atypical cutaneous AML & Mollusca \\
\hline Glomerulonephritis & Uveitis & Isolated refractory thrombocytopenia & Cavitary lung lesions \\
\hline Nephrocalcinosis & Papillitis & Hodgkin's lymphoma & $\begin{array}{l}\text { Herpes virus infections, } \\
\text { increased susceptibility to } \\
\text { double-stranded DNA viruses }\end{array}$ \\
\hline Skin & Episcleritis & Pancytopenia & Urinary tract infections \\
\hline Leukocytoclastic vasculitis & Retinal vasculitis & $\begin{array}{l}\text { T cell large granular lymphocytic } \\
\text { lymphoproliferation }\end{array}$ & Hepatitis \\
\hline Livedo reticularis/racemosa & CRAO & $\begin{array}{l}\text { Multicentric Castleman disease } \\
\text { (mimic) }\end{array}$ & Recurrent tonsillitis \\
\hline Subcutaneous nodular lesions & Cardiac & $\begin{array}{l}\text { Autoimmune lymphoproliferative } \\
\text { syndrome (mimic) }\end{array}$ & \\
\hline Erythema multiforme & Pericarditis & Macrophage activation syndrome & \\
\hline Necrotic ulcers & Myocarditis & Myelofibrosis & \\
\hline Alopecia & Cardiomyopathy & & \\
\hline Neurologic & Long QT syndrome & & \\
\hline TIA & Aortic root enlargement & & \\
\hline Ischemic/hemorrhagic stroke & Myocardial infarction & & \\
\hline Seizures & Gastrointestinal & & \\
\hline Sneddon syndrome & Pancreatitis & & \\
\hline Mental retardation & Mesenteric artery aneurysms & & \\
\hline $\begin{array}{l}\text { Peripheral } \\
\text { neuropathy/mononeuritis } \\
\text { multiplex }\end{array}$ & Mesenteric ischemia & & \\
\hline Cranial neuropathies & Abdominal vein aneurysms & & \\
\hline Pulmonary & Hepatic artery aneurysms & & \\
\hline Pleurisy & Intestinal perforation & & \\
\hline ARDS & Raynaud's & & \\
\hline & Digital necrosis & & \\
\hline
\end{tabular}

seem to correlate with one of the three proposed categories, Lee and colleagues propose that the phenotypes of DADA2 represent a spectrum rather than distinct entities, as demonstrated by the R169Q missense variant, which was found in all the phenotypic categories [73••].

\section{Epidemiology of DADA2}

The estimated prevalence of DADA2 could be as high as 4:100,000, based on allele frequencies of in silico-predicted
ADA2 damaging variants [74]. The carrier frequency for the specific mutation, Gly47Arg, is felt to be as high as 1:10 in Georgian-Jewish populations and 1:500 in Turkish populations [74]. The Arg169Gln mutation is estimated to have a carrier frequency of 1:500 in northern European populations (Finnish and Dutch) [36, 49, 74, 75•], and 1:2100 in the general population [41•]. This mutation has also been reported in other European populations including a German cohort with immunodeficiency and/or antibody deficiency and has been proposed to potentially have an association with a lymphoproliferative phenotype [29••, 49]. An Italian variant, Thr360Ala, 
has been identified as well [17•]. These subsets of increased genetic frequency is felt to not only reflect founder population effects but also relative isolation of smaller populations, population bottlenecks, and population expansion that could lead to expansion of variants with deleterious effects [49]. Overall, patients with DADA2 have been identified globally, with reported ethnicities including Japan, Singapore, China, Morocco, Brazil, Middle East, Europe, and North America.

\section{Diagnosis of and Screening for DADA2}

To confirm the diagnosis, ADA2 activity level and/or genetic testing have been used. Enzyme activity testing level is largely based on the degree of inosine production from adenosine abstracts of patient plasma. Some study groups use the dried plasma spot method, where plasma is prepared from blood samples and applied to Guthrie filter cards [64•]. Filter cards are then dried and enzyme activity is determined via highperformance liquid chromatography [2••]. Caorsi and colleagues based ADA 2 enzyme activity by measuring concentration of inosine and adenosine levels from adenosinestimulated monocytes with or without an ADA1 inhibitor. Lower enzyme activity has correlated with severity of disease in many cases [17•]. Heterozygotes have been shown to have lower levels than normal controls, with variable levels of clinical symptoms [17•].

Genetic testing, whether this is gene-targeted or comprehensive genomic testing, can help confirm the diagnosis. Many studies continue to use Sanger sequencing for targeted gene sequencing of the ADA2 gene (e.g., of all 10 exons of the gene) and/or to confirm the exact mutation within the gene after larger sequencing has been performed [36]. Other studies have used next-generation sequencing as part of a broader approach, including whole exome (WES) or whole genome sequencing (WGS) [76]. Case studies with patients with low ADA2 activity and classic phenotypes but without identifiable mutations raise the question of mutations in introns or other non-coded parts of the gene [17•]. Comprehensive genomic testing also allows for detection of other concurrent genetic mutations that could be confounding the diagnosis. Rama and colleagues proposed a diagnostic algorithm for advanced genetic testing in those with a high clinical suspicion of DADA2. Patients with features of inflammation (e.g., fever and elevated CRP), cutaneous or neurologic features of vasculitis, and recurrent or chronic disease course in adults would benefit from further targeted Sanger sequencing of the ADA2 gene [20•]. Somez and colleagues recommended the addition of hematologic manifestations and parental consanguinity to this algorithm [77].

Currently, the decision to screen for DADA2 is largely based on physician discretion. Some have proposed screening PAN patients with early disease (under age 10), other family members with PAN, certain manifestations (skin, neurologic, cerebral, or bleeding) or resistant disease [78]. A North American cohort screening of 117 adultonset PAN patients showed that over $3 \%$ of patients were homozygous or compound heterozygous for ADA2 gene mutations $[79 \bullet \bullet]$. While the prevalence of DADA2 is low in adult-onset PAN, consideration could be made for screening those with a familial predisposition for PAN, arterial strokes, hematologic manifestations, or immunologic manifestations.

\section{Treatment of DADA2}

Early treatment is important to prevent potentially devastating complications. It has become apparent that specific hematologic and immunologic phenotypes may not respond to the same therapies as those with vasculitic phenotypes [73••]. While in the acute phase, high-dose systemic glucocorticoids can reduce inflammation, most patients have refractory or relapsing disease upon attempts to taper [17•]. For patients with a vasculitic-predominant phenotype, TNF- $\alpha$ inhibition has been shown to be highly efficacious $[16,78,80]$. AntiTNF- $\alpha$ therapy has strong protective effects against stroke $\left[40^{\bullet}, 80^{\bullet} \cdot\right]$. There has not been enough data to support one TNF- $\alpha$ inhibitor over another, with most receiving etanercept, adalimumab, or infliximab $[1 \bullet \bullet, 2 \bullet, 32 \bullet, 39 \bullet$. TNF- $\alpha$ inhibitors have no apparent effect on ADA2 enzyme activity levels $\left[80^{\bullet} \cdot\right]$. Long-term, possibly lifelong, use of TNF- $\alpha$ inhibitors has been proposed because of the risk of relapse with therapy cessation, especially in those with vasculitis and CNS manifestations $[80 \bullet \bullet$.

Patients with immunodeficiency and cytopenia-driven phenotypes tend to be less responsive to TNF- $\alpha$ inhibition. These patients may be candidates for hematopoietic stem cell transplantation (HSCT). Successful HSCT has been reported in twenty-one patients with DADA2 to date $[25,26 \bullet, 28,31 \bullet$, $63,67,68 \bullet$ ]. All patients had resolution of disease manifestations (including cytopenias, immune cell deficiencies, and vasculitis), normalization of ADA2 levels, and reduction of key cytokines (TNF- $\alpha$, IFN- $\alpha$, and IL-6) [68••]. Several patients required more than one transplant; two of whom had received their initial transplant from a healthy sibling later found to have ADA2 gene mutations. Thus, matched allogeneic donors may be preferred, as healthy siblings are often heterozygotes and could have subclinical disease or delayedonset disease. Three of the total twenty-one patients required additional stem cell boosts following decreased donor chimerism with their initial transplant $[67,68 \cdot \bullet]$. Hashem and colleagues have successfully used a reduced conditioning regimen, raising consideration that these DADA2 patients' baseline immunodeficiency may reduce risk for rejection [81•]. This also raises the question that graft lymphocytes may also 
have survival advantage over ADA2-deficient cells; therefore, nonmyeloablative regimens may be successful.

Reported complications from the HSCTs included acute/ chronic graft-versus-host disease, viral reactivation, other severe post-HSCT infections, post-HSCT autoimmune phenomena, and pineal gland hemorrhage $[26 \bullet, 28,63,68 \bullet \cdot$. The potential for a heightened state of inflammation in DADA2 during the peri-transplant period could affect engraftment and the overall success of the transplant [26*]. This heightened inflammatory state could also increase risk for CVA in the pre- and post-transplant periods [26•]. Two patients had veno-occlusive disease complicating the transplant, requiring acute fluid restriction [68••]. The decreased endothelial integrity in DADA2 patients possibly increases the risk for venoocclusive disease in these patients undergoing HSCT.

A number of other therapies have been trialed, many of which are used as first-line therapies for PAN. Nonspecific anti-inflammatory medications like NSAIDs and colchicine have been used, especially when the patient is initially suspected to have concurrent FMF. Stronger immunosuppressive agents including mycophenolate mofetil, azathioprine, cyclosporine, sirolimus, tacrolimus, methotrexate, cyclophosphamide, and rituximab have also been trialed in isolated cases with success $[50,71]$. Thalidomide achieved complete response in a small number of Italian patients; however, its potential toxicities, including fetal toxicity and peripheral neuropathy, must be considered [17•]. Other than in a single patient mimicking multicentric Castleman disease, IL-6 blockade has not been successful in many cases $[24,25,55]$. Anakinra was not found to be effective in an Italian patient with vasculitis-predominant manifestations [17॰]. Canakinumab has been effective in a patient with renal amyloidosis and heterozygous for the FMF gene [53]. Cyclosporine was used for cytopenia-predominant disease with efficacy; however, it was ultimately stopped for treatmentrelated adverse effects with a rapid return of cytopenias [57]. Pentoxifylline was used for a patient with mononeuritis multiplex and cutaneous manifestations, however with incomplete control of livedo reticularis [46]. IVIG has been used for hypogammaglobulinemia and recurrent infections, but was not enough to reduce other disease manifestations [64•]. Monthly fresh frozen plasma infusions replace ADA2 levels, but the effect is too transient for long-term effectiveness $[32 \bullet, 40 \bullet, 80 \bullet \bullet$. While anti-platelet therapy has been used successfully in Kawasaki's disease, there is a theoretical potential for these therapies to worsen hemorrhagic infarcts or lead to hemorrhagic conversion of ischemic infarcts in patients with DADA2.

Future therapies that could change the course of the disease include recombinant ADA2. Gene therapy or gene editing has been proposed, although models have not been developed. Treatment targets including modulation of adenosine receptors, modulation of adenosine-specific NET formation, or the interaction between NET mediators and macrophages are also potential treatment targets $[13 \bullet \bullet$.
There are no guidelines about when to treat patients, especially given the broad spectrum of disease and disease severity. Healthy heterozygotes, often healthy family members of index cases, and asymptomatic genetically proven DADA2 patients are probably safe to monitor for the development of any DADA2 symptoms. For these patients, starting a TNF- $\alpha$ inhibitor at early onset of disease could prevent devastating complications.

\section{Conclusions}

DADA2 demonstrates how single mutations in the gene encoding a monogenic metabolic pathway can result in highly variable, multi-organ disease with potential for high morbidity and mortality. Early identification and diagnosis of this phenotype has significant treatment implications and can dramatically change the disease course. Allele frequency is not limited to endogamous cultures, although it is higher in these populations, and this disease is likely more prevalent than what is currently reported. Awareness of this disease by pediatricians, internists, hematologists, immunologists, infectious disease physicians, hepatologists, and rheumatologists is essential in detection and early management of these patients. A low threshold for screening is important for adults and children with PAN, especially those with affected family members and those who do not respond to conventional therapies. A comprehensive approach to treatment, from both the medical and the patient community, may be the key to developing ongoing effective therapies for this disease.

\section{Compliance with Ethical Standards}

Conflict of Interest The authors declare that they have no conflicts of interest.

Human and Animal Rights and Informed Consent This article does not contain any studies with human or animal subjects performed by any of the authors.

\section{References}

Papers of particular interest, published recently, have been highlighted as:

- Of importance

•- Of major importance

1.• Navon Elkan P, Pierce SB, Segel R, Walsh T, Barash J, Padeh S, et al. Mutant adenosine deaminase 2 in a polyarteritis nodosa vasculopathy. N Engl J Med. 2014;370(10):921-31. https://doi.org/10. 1056/NEJMoa1307362. One of the two founding study groups to describe DADA2.

2.• Zhou Q, Yang D, Ombrello AK, Zavialov AV, Toro C, Zavialov $\mathrm{AV}$, et al. Early-onset stroke and vasculopathy associated with 
mutations in ADA2. N Engl J Med. 2014;370(10):911-20. https:// doi.org/10.1056/NEJMoa1307361. One of the two founding study groups to describe DADA2.

3. Fredholm BB. Adenosine, an endogenous distress signal, modulates tissue damage and repair. Cell Death Differ. 2007;14(7): 1315-23. https://doi.org/10.1038/sj.cdd.4402132.

4. Hasko G, Linden J, Cronstein B, Pacher P. Adenosine receptors: therapeutic aspects for inflammatory and immune diseases. Nat Rev Drug Discov. 2008;7(9):759-70. https://doi.org/10.1038/ $\operatorname{nrd} 2638$

5.• Kaljas Y, Liu C, Skaldin M, Wu C, Zhou Q, Lu Y, et al. Human adenosine deaminases ADA1 and ADA2 bind to different subsets of immune cells. Cell Mol Life Sci. 2017;74(3):555-70. https://doi. org/10.1007/s00018-016-2357-0. Update in physiology of ADA1 and ADA2, and description of the types of cells to which ADA1 and ADA2 bind.

6.• Zavialov AV, Engstrom A. Human ADA2 belongs to a new family of growth factors with adenosine deaminase activity. Biochem J. 2005;391(Pt 1):51-7. https://doi.org/10.1042/BJ20050683. One of the original articles describing function of $\mathrm{ADA} 2$ and its role as growth factor.

7. Buckley RH. Molecular defects in human severe combined immunodeficiency and approaches to immune reconstitution. Annu Rev Immunol. 2004;22:625-55. https://doi.org/10.1146/annurev. immunol.22.012703.104614.

8.• Zavialov AV, Yu X, Spillmann D, Lauvau G, Zavialov AV. Structural basis for the growth factor activity of human adenosine deaminase ADA2. J Biol Chem. 2010;285(16):12367-77. https:// doi.org/10.1074/jbc.M109.083527. One of the original papers describing physiology of ADA2 and how its structure relates to function.

9. Dolezal T, Dolezelova E, Zurovec M, Bryant PJ. A role for adenosine deaminase in Drosophila larval development. PLoS Biol. 2005;3(7):e201. https://doi.org/10.1371/journal.pbio.0030201.

10. Iijima R, Kunieda T, Yamaguchi S, Kamigaki H, Fujii-Taira I, Sekimizu K, et al. The extracellular adenosine deaminase growth factor, ADGF/CECR1, plays a role in Xenopus embryogenesis via the adenosine/P1 receptor. J Biol Chem. 2008;283(4):2255-64. https://doi.org/10.1074/jbc.M709279200.

11.• Zavialov AV, Gracia E, Glaichenhaus N, Franco R, Zavialov AV, Lauvau G. Human adenosine deaminase 2 induces differentiation of monocytes into macrophages and stimulates proliferation of $\mathrm{T}$ helper cells and macrophages. J Leukocyte Biol. 2010;88(2):27990. https://doi.org/10.1189/jlb.1109764. The first article to describe how ADA2 induces macrophage differentiation.

12. Belot A, Wassmer E, Twilt M, Lega JC, Zeef LA, Oojageer A, et al. Mutations in CECR1 associated with a neutrophil signature in peripheral blood. Pediatr Rheumatol Online J. 2014;12:44. https://doi. org/10.1186/1546-0096-12-44.

13.• Carmona-Rivera C, Khaznadar SS, Shwin KW, Irizarry-Caro JA, O'Neil LJ, Liu Y, et al. Deficiency of adenosine deaminase 2 triggers adenosine-mediated NETosis and TNF production in patients with DADA2. Blood. 2019;134(4):395-406. https://doi.org/10. 1182/blood.2018892752. Key study of dysregulated NETosis and DADA2.

14. Villanueva E, Yalavarthi S, Berthier CC, Hodgin JB, Khandpur R, Lin AM, et al. Netting neutrophils induce endothelial damage, infiltrate tissues, and expose immunostimulatory molecules in systemic lupus erythematosus. J Immunol. 2011;187(1):538-52. https://doi.org/10.4049/jimmunol.1100450.

15. Kessenbrock K, Krumbholz M, Schonermarck U, Back W, Gross WL, Werb Z, et al. Netting neutrophils in autoimmune smallvessel vasculitis. Nat Med. 2009;15(6):623-5. https://doi.org/10. 1038/nm.1959.

16. Chong-Neto HJ, Segundo GRS, Bandeira M, Chong-Silva DC, Rosario CS, Riedi CA, et al. Homozygous splice ADA2 gene mutation causing ADA-2 deficiency. J Clin Immunol. 2019;39(8): 842-5. https://doi.org/10.1007/s10875-019-00697-2.

17. Caorsi R, Penco F, Grossi A, Insalaco A, Omenetti A, Alessio M, et al. ADA2 deficiency (DADA2) as an unrecognised cause of early onset polyarteritis nodosa and stroke: a multicentre national study. Ann Rheum Dis. 2017;76(10):1648-56. https://doi.org/10.1136/ annrheumdis-2016-210802. Large Italian cohort study with emphasis on broad clinical manifestations and treatments that had been used to date, including thalidomide.

18. Hara T, Ando K, Tsurumi H, Moriwaki H. Excessive production of tumor necrosis factor-alpha by bone marrow $\mathrm{T}$ lymphocytes is essential in causing bone marrow failure in patients with aplastic anemia. Eur J Haematol. 2004;73(1):10-6. https://doi.org/10. 1111/j.1600-0609.2004.00259.x.

19. Insalaco A, Moneta GM, Pardeo M, Caiello I, Messia V, Bracaglia $\mathrm{C}$, et al. Variable clinical phenotypes and relation of interferon signature with disease activity in ADA2 deficiency. J Rheumatol. 2019;46(5):523-6. https://doi.org/10.3899/jrheum.180045.

20. Rama M, Duflos C, Melki I, Bessis D, Bonhomme A, Martin H, et al. A decision tree for the genetic diagnosis of deficiency of adenosine deaminase 2 (DADA2): a French reference centres experience. Eur J Hum Genet. 2018;26(7):960-71. https://doi.org/10. 1038/s41431-018-0130-6. Larger cohort study with emphasis on weighting disease characteristics for diagnostic purposes.

21. Skrabl-Baumgartner A, Plecko B, Schmidt WM, Konig N, Hershfield M, Gruber-Sedlmayr U, et al. Autoimmune phenotype with type I interferon signature in two brothers with ADA2 deficiency carrying a novel CECR1 mutation. Pediatr Rheumatol Online J. 2017;15(1):67. https://doi.org/10.1186/s12969-0170193-x.

22. Uettwiller F, Sarrabay G, Rodero MP, Rice GI, Lagrue E, Marot Y, et al. ADA2 deficiency: case report of a new phenotype and novel mutation in two sisters. RMD Open. 2016;2(1):e000236. https:// doi.org/10.1136/rmdopen-2015-000236.

23. Lee PY. Vasculopathy, immunodeficiency, and bone marrow failure: the intriguing syndrome caused by deficiency of adenosine deaminase 2. Front Pediatr. 2018;6:282. https://doi.org/10.3389/ fped.2018.00282.

24. Van Nieuwenhove E, Humblet-Baron S, Van Eyck L, De Somer L, Dooley J, Tousseyn T, et al. ADA2 deficiency mimicking idiopathic multicentric Castleman disease. Pediatrics. 2018;142(3). https:// doi.org/10.1542/peds.2017-2266.

25. Liu L, Wang W, Wang Y, Hou J, Ying W, Hui X, et al. A Chinese DADA2 patient: report of two novel mutations and successful HSCT. Immunogenetics. 2019;71(4):299-305. https://doi.org/10. 1007/s00251-018-01101-w.

26. Van Eyck L Jr, Hershfield MS, Pombal D, Kelly SJ, Ganson NJ, Moens L, et al. Hematopoietic stem cell transplantation rescues the immunologic phenotype and prevents vasculopathy in patients with adenosine deaminase 2 deficiency. J Allergy Clin Immunol. 2015;135(1):283-7 e5. https://doi.org/10.1016/j.jaci.2014.10.010. One of the first studies to describe DADA2 patients treated with HSCT.

27. Hashem H, Egler R, Dalal J. Refractory pure red cell aplasia manifesting as deficiency of adenosine deaminase 2. J Pediatr Hematol Oncol. 2017;39(5):e293-e6. https://doi.org/10.1097/MPH. 0000000000000805.

28. Barzaghi F, Minniti F, Mauro M, Bortoli M, Balter R, Bonetti E, et al. ALPS-like phenotype caused by ADA2 deficiency rescued by allogeneic hematopoietic stem cell transplantation. Front Immunol. 2018;9:2767. https://doi.org/10.3389/fimmu.2018.02767.

29.• Schepp J, Proietti M, Frede N, Buchta M, Hubscher K, Rojas Restrepo J, et al. Screening of 181 patients with antibody deficiency for deficiency of adenosine deaminase 2 sheds new light on the disease in adulthood. Arthritis Rheumatol. 2017;69(8):1689-700. 
https://doi.org/10.1002/art.40147. Larger cohort of DADA2 patients with focus on the immunodeficiency phenotype.

30. Tull TJ, Martin B, Spencer J, Sangle S, Chua S, McGrath JA, et al. Sneddon syndrome associated with two novel ADA2 gene mutations. Rheumatology. 2019;59:1448-50. https://doi.org/10.1093/ rheumatology/kez446.

31. Gibson KM, Morishita KA, Dancey P, Moorehead P, Drogemoller B, Han X, et al. Identification of novel adenosine deaminase 2 gene variants and varied clinical phenotype in pediatric vasculitis. Arthritis Rheumatol. 2019;71(10):1747-55. https://doi.org/10. 1002/art.40913. Larger pediatric cohort of DADA2, including subjects of Asian descent, and novel genetic mutation.

32. Batu ED, Karadag O, Taskiran EZ, Kalyoncu U, Aksentijevich I, Alikasifoglu M, et al. A case series of adenosine deaminase 2deficient patients emphasizing treatment and genotype-phenotype correlations. J Rheumatol. 2015;42(8):1532-4. https://doi.org/10. 3899/jrheum.150024. Case series of DADA2 patients emphasizing broader spectrum of disease, including progressive renal involvement (FSGS, collapsing variant, amyloidosis).

33. Fellmann F, Angelini F, Wassenberg J, Perreau M, Arenas Ramirez N, Simon G, et al. IL-17 receptor A and adenosine deaminase 2 deficiency in siblings with recurrent infections and chronic inflammation. J Allergy Clin Immunol. 2016;137(4):1189-96 e1-2. https://doi.org/10.1016/j.jaci.2015.07.053.

34. Bulut E, Erden A, Karadag O, Oguz KK, Ozen S. Deficiency of adenosine deaminase 2; special focus on central nervous system imaging. J Neuroradiol. 2019;46(3):193-8. https://doi.org/10. 1016/j.neurad.2018.05.002.

35. Dimachkie MD, Fraga GR, Moura NS, Springer JM. A rare case of adenosine deaminase 2 deficiency presenting with temporal arteritis. J Clin Rheumatol. 2020. https://doi.org/10.1097/RHU. 0000000000001384 Publish Ahead of Print.

36. Westendorp WF, Nederkoorn PJ, Aksentijevich I, Hak AE, Lichtenbelt KD, Braun KP. Unexplained early-onset lacunar stroke and inflammatory skin lesions: consider ADA2 deficiency. Neurology. 2015;84(20):2092-3. https://doi.org/10.1212/WNL. 0000000000001581.

37. Ben-Ami T, Revel-Vilk S, Brooks R, Shaag A, Hershfield MS, Kelly SJ, et al. Extending the clinical phenotype of adenosine deaminase 2 deficiency. J Pediatr. 2016;177:316-20. https://doi.org/ 10.1016/j.jpeds.2016.06.058. Case Series of DADA2 patients with diverse hematologic manifestations; one of the initial cases to propose immunologic manifestations of the disease.

38. Sozeri B, Ercan G, Dogan OA, Yildiz J, Demir F, Doganay L. The same mutation in a family with adenosine deaminase 2 deficiency. Rheumatol Int. 2019. https://doi.org/10.1007/s00296-019-04444-z.

39. Nanthapisal S, Murphy C, Omoyinmi E, Hong Y, Standing A, Berg S, et al. Deficiency of adenosine deaminase type 2 (DADA2): A description of phenotype and genotype in 15 cases. Arthritis Rheumatol. 2016. https://doi.org/10.1002/art.39699. Larger cohort of DADA2 patients, including description of presymptomatic ADA2 patients, and one of the earlier studies to describe treatment with TNF- $\alpha$ inhibitors.

40. Sahin S, Adrovic A, Barut K, Ugurlu S, Turanli ET, Ozdogan H, et al. Clinical, imaging and genotypical features of three deceased and five surviving cases with ADA2 deficiency. Rheumatol Int. 2018;38(1):129-36. https://doi.org/10.1007/s00296-017-3740-3. Larger DADA2 cohort comparing deceased and surviving DADA2 patients, with proposal that anti-TNF therapy may produce better outcomes.

41. Huang Z, Li T, Nigrovic PA, Lee PY. Polyarteritis nodosa and deficiency of adenosine deaminase 2 - shared genealogy, generations apart. Clin Immunol. 2020;215:108411. https://doi.org/10. 1016/j.clim.2020.108411. Key study comparing DADA2 and PAN, with diagnostic and therapeutic implications.
42. Springer JM, Gierer SA, Jiang H, Kleiner D, Deuitch N, Ombrello AK, et al. Deficiency of adenosine deaminase 2 in adult siblings: many years of a misdiagnosed disease with severe consequences. Front Immunol. 2018;9:1361. https://doi.org/10.3389/fimmu. 2018.01361.

43. Elbracht M, Mull M, Wagner N, Kuhl C, Abicht A, Kurth I, et al. Stroke as initial manifestation of adenosine deaminase 2 deficiency. Neuropediatrics. 2017;48(2):111-4. https://doi.org/10.1055/s0036-1597611.

44. Sahin S, Adrovic A, Barut K, Baran S, Tahir Turanli E, Canpolat N, et al. A 9.5-year-old boy with recurrent neurological manifestations and severe hypertension, treated initially for polyarteritis nodosa, was subsequently diagnosed with adenosine deaminase type 2 deficiency (DADA2) which responded to anti-TNF-alpha. Paediatr Int Child Health. 2020;40(1):65-8. https://doi.org/10.1080/ 20469047.2018.1559495.

45. Sahin S, Adrovic A, Kasapcopur O. A monogenic autoinflammatory disease with fatal vasculitis: deficiency of adenosine deaminase 2. Curr Opin Rheumatol. 2020;32(1):3-14. https://doi.org/10.1097/BOR.0000000000000669.

46. Liebowitz J, Hellmann DB, Schnappauf O. Thirty years of followup in 3 patients with familial polyarteritis nodosa due to adenosine deaminase 2 deficiency. J Rheumatol. 2019;46(8): 1059-60. https://doi.org/10.3899/jrheum.180820.

47. Pichard DC, Ombrello AK, Hoffmann P, Stone DL, Cowen EW. Early-onset stroke, polyarteritis nodosa (PAN), and livedo racemosa. J Am Acad Dermatol. 2016;75(2):449-53. https://doi. org/10.1016/j.jaad.2016.01.057.

48. Grossi A, Cusano R, Rusmini M, Penco F, Schena F, Podda RA, et al. ADA2 deficiency due to a novel structural variation in 22q11.1. Clin Genet. 2019;95(6):732-3. https://doi.org/10.1111/ cge. 13518.

49. Trotta L, Martelius T, Siitonen T, Hautala T, Hamalainen S, Juntti $\mathrm{H}$, et al. ADA2 deficiency: clonal lymphoproliferation in a subset of patients. J Allergy Clin Immunol. 2018;141(4):1534-7 e8. https:// doi.org/10.1016/j.jaci.2018.01.012.

50. Keer N, Hershfield M, Caskey T, Unizony S. Novel compound heterozygous variants in CECR1 gene associated with childhood onset polyarteritis nodosa and deficiency of ADA2. Rheumatology. 2016;55(6):1145-7. https://doi.org/10.1093/ rheumatology/kew050.

51. Alaygut D, Alparslan C, Oncel EP, Mutlubas F, Ozdemir T, Yavascan $\mathrm{O}$, et al. A child diagnosed with treatment-resistant polyarteritis nodosa: can the clinical diagnosis be different? Arch Rheumatol. 2019;34(3):338-42. https://doi.org/10.5606/ ArchRheumatol.2019.7075.

52. Meyts I, Aksentijevich I. Deficiency of adenosine deaminase 2 (DADA2): updates on the phenotype, genetics, pathogenesis, and treatment. J Clin Immunol. 2018;38(5):569-78. https://doi.org/10. 1007/s10875-018-0525-8.

53. Kisla Ekinci RM, Balci S, Bisgin A, Hershfield M, Atmis B, Dogruel D, et al. Renal amyloidosis in deficiency of adenosine deaminase 2: successful experience with canakinumab. Pediatrics. 2018;142(5). https://doi.org/10.1542/peds.2018-0948.

54. Martin H, Bursztejn AC, Cuny JF, Sarrabay G, Schmutz JL, Touitou I, et al. Chronic leg ulcer revealing adenosine deaminase 2 deficiency: an atypical presentation. Eur J Dermatol. 2018;28(6): 847-8. https://doi.org/10.1684/ejd.2018.3427.

55. Nihira H, Nakagawa K, Izawa K, Kawai T, Yasumi T, Nishikomori $\mathrm{R}$, et al. Fever of unknown origin with rashes in early infancy is indicative of adenosine deaminase type 2 deficiency. Scand J Rheumatol. 2018;47(2):170-2. https://doi.org/10.1080/03009742. 2017.1324912.

56. Kisla Ekinci RM, Balci S, Hershfield M, Bisgin A, Dogruel D, Altintas DU, et al. Deficiency of adenosine deaminase 2: a case series revealing clinical manifestations, genotypes and treatment 
outcomes from Turkey. Rheumatology. 2020;59(1):254-6. https:// doi.org/10.1093/rheumatology/kez260. Case series describing Turkish cohort of DADA2 patients including a case of renal amyloidosis.

57. Michniacki TF, Hannibal M, Ross CW, Frame DG, DuVall AS, Khoriaty R, et al. Hematologic manifestations of deficiency of adenosine deaminase 2 (DADA2) and response to tumor necrosis factor inhibition in DADA2-associated bone marrow failure. $\mathrm{J}$ Clin Immunol. 2018;38(2):166-73. https://doi.org/10.1007/ s10875-018-0480-4.

58. Lamprecht P, Humrich JY, Diebold I, Riemekasten G. Diagnosis of deficiency of adenosine deaminase 2 with early onset polyarteritis nodosa in an adult patient with a novel compound heterozygous CECR1 mutation. Clin Exp Rheumatol. 2018;36 Suppl 111(2):177.

59. Cipe FE, Aydogmus C, Serwas NK, Keskindemirci G, Boztug K. Novel mutation in CECR1 leads to deficiency of ADA2 with associated neutropenia. J Clin Immunol. 2018;38(3):273-7. https://doi. org/10.1007/s10875-018-0487-x.

60. Sundin M, Marits P, Nierkens S, Kolios AGA, Nilsson J. "Immune" thrombocytopenia as key feature of a novel ADA2 deficiency variant: implication on differential diagnostics of ITP in children. $\mathrm{J}$ Pediatr Hematol Oncol. 2019;41(2):155-7. https://doi.org/10. 1097/MPH.0000000000001132.

61. Arts K, Bergerson JRE, Ombrello AK, Similuk M, Oler AJ, Agharahimi A, et al. Warts and DADA2: a mere coincidence? J Clin Immunol. 2018;38(8):836-43. https://doi.org/10.1007/ s10875-018-0565-0.

62. Alabbas F, Elyamany G, Alsharif O, Hershfield M, Meyts I. Childhood Hodgkin lymphoma: think DADA2. J Clin Immunol. 2019;39(1):26-9. https://doi.org/10.1007/s10875-019-0590-7.

63. Hsu AP, West RR, Calvo KR, Cuellar-Rodriguez J, Parta M, Kelly SJ, et al. Adenosine deaminase type 2 deficiency masquerading as GATA2 deficiency: successful hematopoietic stem cell transplantation. J Allergy Clin Immunol. 2016;138(2):628-30 e2. https://doi. org/10.1016/j.jaci.2016.03.016.

64.• Schepp J, Bulashevska A, Mannhardt-Laakmann W, Cao H, Yang F, Seidl M, et al. Deficiency of adenosine deaminase 2 causes antibody deficiency. J Clin Immunol. 2016, 36(3):179-86. https:// doi.org/10.1007/s10875-016-0245-x. One of the earlier case series describing antibody deficiency and immune dysregulation as manifestations of DADA2.

65. Ghurye RR, Sundaram K, Smith F, Clark B, Simpson MA, Fairbanks L, et al. Novel ADA2 mutation presenting with neutropenia, lymphopenia and bone marrow failure in patients with deficiency in adenosine deaminase 2 (DADA2). Br J Haematol. 2019;186(3):e60-e4. https://doi.org/10.1111/bjh.15896.

66. Maccora I, Frongia I, Azzari C, Ricci S, Cimaz R, Simonini G. A misleading case of deficiency of adenosine deaminase 2 (DADA2): the magnifying glass of the scientific knowledge drives the tailored medicine in real life. Clin Exp Rheumatol. 2018;36(6 Suppl 115):146.

67. Bucciol G, Delafontaine S, Segers H, Bossuyt X, Hershfield MS, Moens L, et al. Hematopoietic stem cell transplantation in ADA2 deficiency: early restoration of ADA2 enzyme activity and disease relapse upon drop of donor chimerism. J Clin Immunol. 2017;37(8):746-50. https://doi.org/10.1007/s10875-017-0449-8.

68.• Hashem H, Kumar AR, Muller I, Babor F, Bredius R, Dalal J, et al. Hematopoietic stem cell transplantation rescues the hematological, immunological, and vascular phenotype in DADA2. Blood. 2017;130(24):2682-8. https://doi.org/10.1182/blood-2017-07798660. Key study describing the first fourteen patients to receive HSCT for DADA2 and initial outcomes.

69. Karacan I, Balamir A, Ugurlu S, Aydin AK, Everest E, Zor S, et al. Diagnostic utility of a targeted next-generation sequencing gene panel in the clinical suspicion of systemic autoinflammatory diseases: a multi-center study. Rheumatol Int. 2019;39(5):911-9. https://doi.org/10.1007/s00296-019-04252-5.

70. Akgun-Dogan O, Simsek-Kiper PO, Taskiran E, Lissewski C, Brinkmann J, Schanze D, et al. ADA2 deficiency in a patient with Noonan syndrome-like disorder with loose anagen hair: the cooccurrence of two rare syndromes. Am J Med Genet A. 2019;179(12):2474-80. https://doi.org/10.1002/ajmg.a.61363.

71. Gunthner R, Wagner M, Thurm T, Ponsel S, Hofele J, LangeSperandio B. Identification of co-occurrence in a patient with Dent's disease and ADA2-deficiency by exome sequencing. Gene. 2018;649:23-6. https://doi.org/10.1016/j.gene.2018.01. 060 .

72.• https://infevers.umai-montpellier.fr/web/search.php?n=20. Accessed 1 Mar 2020. Online database for DADA2 sequence variants.

73.• Lee PY, Kellner ES, Huang Y, Furutani E, Huang Z, Bainter W, et al. Genotype and functional correlates of disease phenotype in deficiency of adenosine deaminase 2 (DADA2), J Allergy Clin Immunol. 2020. https://doi.org/10.1016/j.jaci.2019.12.908. Key review focusing on genotype-phenotype correlations.

74. Aksentijevich IMN, Barron K. Adenosine deaminase 2 deficiency. Seattle: GeneReviews [Inernet]; 2019.

75. Van Montfrans JM, Hartman EA, Braun KP, Hennekam EA, Hak EA, Nederkoorn PJ, et al. Phenotypic variability in patients with ADA2 deficiency due to identical homozygous R169Q mutations. Rheumatology. 2016;55(5):902-10. https://doi.org/10.1093/ rheumatology/kev439. Key case series emphasizing the spectrum of phenotypic heterogeneity in DADA2 patients with the same DADA2 genotype.

76. Claassen D, Boals M, Bowling KM, Cooper GM, Cox J, Hershfield M, et al. Complexities of genetic diagnosis illustrated by an atypical case of congenital hypoplastic anemia. Cold Spring Harbor Mol Case Stud. 2018;4(6). https://doi.org/10.1101/mcs. a003384.

77. Sonmez HE, Batu ED, Taskiran EZ, Alikasifoglu M, Bilginer Y, Ozen S. Genetic testing for DADA2: how can we avoid missing patients? Eur J Hum Genet. 2018;26(11):1563-5. https://doi.org/ 10.1038/s41431-018-0240-1.

78. Krutzke S, Horneff G. Treatment of two male children suffering from deficiency of adenosine deaminase type 2 (DADA2) with TNF-inhibitor etanercept. J Clin Rheumatol. 2019. https://doi.org/ 10.1097/RHU.0000000000001145 Publish Ahead of Print.

79.• Schnappauf OSM, Aksentijevich I, Kastner DL, Grayson PC, Cuthbertson D, Carette S, et al. Screening of patients with adultonset idiopathic polyarteritis nodosa for deficiency of adenosine deaminase 2 [abstract]. Arthritis Rheumatol. 2018;70(suppl 10). https://acrabstracts.org/abstract/screeningof-patients-with-adultonset-idiopathic-polyarteritisnodosa-for-deficiency-of-adenosinedeaminase-2/. Accessed 2 Aug 2020. North American cohort screening PAN patients for DADA2.

80.• Ombrello AK, Qin J, Hoffmann PM, Kumar P, Stone D, Jones A, et al. Treatment strategies for deficiency of adenosine deaminase 2. N Engl J Med. 2019;380(16):1582-4. https://doi.org/10.1056/ NEJMc1801927. Key study into efficacy of anti-TNF therapy in DADA2.

81. Hashem H, Vatsayan A, Gupta A, Nagle K, Hershfield M, Dalal J. Successful reduced intensity hematopoietic cell transplant in a patient with deficiency of adenosine deaminase 2. Bone Marrow Transplant. 2017;52(11):1575-6. https://doi.org/10.1038/bmt. 2017.173. First study to describe a reduced intensity HSCT regimen in a DADA2 patient.

Publisher's Note Springer Nature remains neutral with regard to jurisdictional claims in published maps and institutional affiliations. 